\title{
Supply Chain Planning in Defence Operations: a Review from Great Alexander Time to the Present
}

\author{
Lazaros K. Rizopoulos, \\ University of Peloponnese, School of Economics, Management \& Informatics, \\ Department of Economics, Tripoli, Greece, \\ Dimitrios D. Thomakos, \\ University of Peloponnese, School of Economics, Management \& Informatics, \\ Department of Economics, Tripoli, Greece,
}

\begin{abstract}
We review the Supply Chain (SC) planning in Defence operations. Our main focus is an exploration of the literature to identify the significant factors concerning SC planning and the way they affect the implementation of Decision Making Processes (DMP) in (primarily) military operations. We take as our starting point the logistics of Alexander the Great's army, to identify the key factors that led to his legendary success and to understand how these factors influenced his strategic decisions. We then review the practices, and evaluate the effectiveness, of countries and international bodies that have already implemented such SC management and planning systems to assist in their defence activities' decisions. Then, we illustrate the literature review with specific modern day examples of military deployment. Although many countries have invested in IT systems which may provide up to date information and cost-effectiveness suggestions, nevertheless, the utility of these systems in the defence sector, seems to be often surrounded by emotions and private or vested interests. Our research thus far suggests that there are substantial benefits to be gained by adopting a relevant decision framework to be implemented among military activities. At the end we attempt an identification of the key factors concerning SC planning since Alexander's time and their effectiveness level in recent defence operations among other existing DMP tools.
\end{abstract}

Keywords: Supply Chain planning, Defence operations, Decision Making Processes, Alexander the Great

\section{Introduction}

SC planning tools, as well as DMP methods, have been accepted as a substantial positive factor by the majority of highrank officials and key authorities in active, real-time decision-making. It is still controversial though, which are the exact positive outcomes and whether or not substantial economic benefits are potential due to the optimization of SC planning in an integrated way among decision-related issues. Referring to the DMP, the defence sector seems not to heavily engage data-driven methods widely but most likely, convenient on-site solutions. Nevertheless, some countries or international bodies - like United States (US), United Kingdom (UK) and NATO - have already in place relevant frameworks to assist SC planning procedures. Moreover, there are studies that reveal that the defence sector may anticipate positive outcomes related to business and scientific methods. This study -as a part of an ongoing research designed to end up with a Decision Model which leads to the optimal SC forecasting and planning of military operations- will try to identify and analyse the key factors concerning SC planning in defence operations. We are after a suitable, real-life decision-making model to optimize the SC and Logistic support systems among the defence sector, so as to operate both efficiently and sustainable. Optimization methods may contribute in the most positive way to reform Logistics and SC replenishment procedures and should not be undertaken just as a tool for protecting the service budgets and salaries or satisfying interest groups. 


\section{Design and Methodology}

A proper literature review is a first milestone in order to explore past ideas and to support the development of guidelines with certain steps to avoid bias distortions during research and data analysis. It may also provide the necessary criticism among all research steps. We are thus launching our research agenda by focusing on past and present SC practices in order to be able to understand what has been done so far.

Quantitative research involves the measurement of SC management performance, and many researchers recognize benchmarking performance in Defence sector as the biggest challenge. Qualitative methods concerning the assessment of SC management may include surveys, interviews, case studies and theoretical analyses. The value of a qualitative approach depends on the expert level of participants, the quality of the interviews and the cooperation of the participants. Although both methods may apply to the present study and both are involved in the ongoing research, there are inherent difficulties in collection of sufficient quantitative data for analysis. Disclosure issues are very crucial among the Defence sector and the public availability of them is challenging. Therefore, it was critical to choose the research method cautiously, with respect to its features and the researcher's objectives.

Worldwide, since the end of the Cold War and more drastically since after 9/11 terror attack, Armed Forces (AFs) have delivered changes their static posture to a one that should be capable of supporting expeditionary military operations far from their national military bases. That doctrine shift required investments in training, transport assets and upgraded supply chain and logistics capabilities, so, forecasting, modelling and simulation in SC chain planning should be more integrated among DMP. So, the need for action and evolution of the present models is crucial. Models should be more sophisticated to capture and tackle with the dynamics of demanding national security issues, future hybrid threats and extended needs (Wiles \& Chinn, 2010).

This study will try to identify and evaluate significant factors concerning with SC planning, as a part of the ongoing research. It mainly uses the literature review method and utilizes Grounded Theory method tools (Charmaz, 1983). Grounded theory has been selected because it may generate a theory that can be used as a forerunner for further investigation of a phenomenon. Also, allows other qualitative research techniques and quantitative methods or a combination of both to be used in order to test, verify or extend the qualitative propositions that become apparent from the research (Bryant, 2002). Moreover, useful results can be produced among the complexities of Defence sector context, and the researcher may incorporate them into the understanding of the phenomenon. Personal interviews from Defence/business sector experts and key official authorities were conducted. These methods have frequently been used in other studies, particularly in complex business and/or military sector and are considered to be appropriate for the present study. The combined results were used to provide recommendations.

First of all, an initial review of the existing documentation was performed as well as of the existing frameworks, legislation, and relevant policies in the military context and generic. As a result, a particular number and range of countries that have already implemented such tools in their Defence activities were being identified and reviewed in conjunction with the accessibility of them, thus resulting in a representative sample. The review was being employed to identify the significant factors concerned with the successful SC planning of Alexander the Great campaign and modern era military operations. Besides, following an initial stakeholder analysis, personal interviews have been taken place from key authorities' officials, and Defence and business SC experts, to critically assess Alexander's achievements, evaluate the key factors which influenced his DMP. Experts also identified certain modern era military operations under the shadow of Alexander's logistics. Experts were cautiously selected regarding their experience, participation and knowledge level among defence sector's operations and business SC planning procedures as also as their availability. The experts' sample consists of former AFs' Chiefs of Staff, retired Generals and Lieutenant Generals, Ambassadors, former Defence Attaches, high-rank military Officers and civilian officials with SC planning authority. During the interviews, open-ended questions were used to define the concepts and identify the key factors. Presentation of the preliminary data collection and the initial results of the review was avoided in order to exclude bias distortions. The combined results of the literature review and the experts' qualitative data were examined to identify the key factors and outline the evidence of SC frameworks effectiveness.

\section{Literature Review}

\section{Alexander the Great's Logistics Achievements}


Most of the countries confront the need to safeguard their national interests and maintain their global military role, if any, despite the demanded budget restraints. So, Defence sector and AFs are - like any other public sector's agency - struggling with lower budgets and social pressure worldwide to secure their national security interests ${ }^{1}$. Despite the need for innovative strategies and the fact that many countries have already invested in IT systems which should have been able to provide up-to-date information and cost-effective solutions, it is commonly accepted that Defence sector seems to be often surrounded by emotions. Moreover, actual peacetime planning is revealed to be rather more a typical outcome of various interest groups. However, the world remains a dangerous place, and AFs should be ready and capable of doing more with less. They should be able to maintain operational capability under current or future pressures on budgets, to promote sustainability and to shift from the traditional model of strategic planning to a more flexible and integrated one.

According to the literature, $\mathrm{SC}$ is a substantial element of strategic planning and can contribute the most to the effectiveness level of relevant DMP. The notion that "logistics are fundamental to the generation and maintenance of fighting power in every environment" (UK Ministry of Defence, 2003) is not new, but should be fully implemented in everyday practice and positively affect the military mindset. SC is one of the most important areas of military logistics. It is defined as "the set of processes, infrastructure, equipment, and personnel that moves a force to the theatre of operations and sustains it by maintaining stocks and transporting additional goods and people" (Wiles \& Chinn, 2010). SC forecasting, planning, and execution orders should cover the military operations' replenishment needs around the world, no matter how far away from the home-base the troops operate. Although most military operations emphasize on planning and enhancing the fighting power of battle itself, history reveals that logistics and SC are the most valuable assets of warfare since the campaigns of Alexander the Great (Andrejevas, 2010). However, for the commanders of US, UK and NATO Allied Joint Forces, the importance of logistics has been acknowledged just since after the overseas operations of the 1990s. Logistical difficulties in the modern era deployments of AFs have proved the notion that no army, however well equipped may be, can function conveniently without an exceptional SC plan (Sticz, 2008).

Studying Macedonian Army's legendary success and Alexander's ability to deliver the most impressive SC plan and embrace the proper strategic insights as well, is constructive and valuable for all military leaders. Until today, Alexander the Great is considered a strategic pioneer, but it is his logistical solutions, "the complexity and smoothness of which offers ... the clearest signs of his genius" (Keegan, 1988). Review of Great Alexander's campaign profoundly recognizes that logistics and SC were the vital assets of his legendary success and identifies the key factors that influenced his strategic decisions (Pagonis \& Cruikshank, 1992).

Alexander the Great was the first who successfully integrated and dynamically applied the logistics and SC planning into his strategic decision-making process (Engels, 1980). The review of his achievements and the way he utilized the troops' formations and movements, and the incorporation of new weapons as well, demonstrates that Alexander's genius military doctrine led to significant development of military mindset. His excellent performance in rigorous and hostile environment, the efficient deployment far away from his home base and the demonstrated flexibility are only some of the signs of his military innovative way of planning. Even more, the sophisticated and sustained SC replenishment of his army is considered as the key factor of his DMP which led to legendary victory (Van Mieghem, 1998).

He started his campaigns from Macedonia region in Greece and finally conquered countries including Egypt, Persia, Syria, and India. His achievements were the systematic result of operational and proactive logistics planning and precise precautions. SC planning was the base of every Alexander's military plan and strategic decision (Fuller, 2004). Due to his strategic and innovative logistic action, Alexander has been acknowledged as a legend, has inspired military mindset and warfare art, and has been the epitome among other leaders, including Julius Caesar and Napoleon (Van Mieghem, 1998).

As Donald W. Engels (1980) describes, before Alexander era, provisions -arms, food, and other supplies- were transferred and relocated by servants, wagons, and carts. To minimize the number of supplies needed and reduce the SC burden, Alexander enforced that supplies would have been carried by the military force itself. Soldiers' spouses have also been excluded. To anticipate the consequences of his decision, he permitted scheduled visits and encouraged marriages with locals. As a result, the total number of the military force was the minimum required, the needed transportation means were reduced and the servants were minimized to one for every four soldiers. Consequently, troops' speed, flexibility and mobility

\footnotetext{
1 Notes From the Chairman. (2016, September 4). Retrieved September 4, 2016, from https://www.foreignaffairs.com/interviews/201608-01/notes-chairman 
were substantially increased, and Alexander was capable of ordering accelerated marching and force attack. Additionally, Alexander transportation replacements -oxen to horses- resulted in transferring the necessary equipment without lowering troops' tempo. These strategic decisions did also reduce the total number of needed personnel and provisions (Andrejevas, 2010).

Moreover, because his troops could not have been self-sufficient for long distances, he decided to use ships as supply bases and he carefully selected the marching routes, which were close to rivers or coasts. Otherwise, the hostile areas of the Central Asia, the scarcity of resources and the potential reduction of troops' tempo might have had a dramatic effect on his campaign. If close to water routes were inconvenient, he could adapt planning to stay on track with fertile valleys and the Persian network road system. In Persia, there was a path between all cities and stationed supplies every fifteen to twenty miles to keep Darius Army informed, secure, and well provisioned. Alexander took advantage of it. Despite the decisions mentioned above, Alexander wherever he could not remain self- sustained -especially in far from sea or rivers areas- he ensured the host nation support (Van Mieghem, 1998). He had secured army's provision in advance with local officials, -locals were surrendered prior entering their territory- and precisely selected the invasion timetable following the local agricultural production and harvest schedule. That integrated and flexible Alexander's strategic planning concerning SC, as described before, is regularly found during his campaign (Pederson, 1998).

Additionally, the review demonstrates his ability to integrate and implement political, diplomatic and economic power tools in various ways, coordinated with the military force to achieve the planned goals and objectives. For instance, in order to moderate the needed fight power for his campaign, Alexander at the beginning of his campaign decided to ultimately destroy the city of Thebes, thus influencing next cities to surrender prior fighting. The intelligence service was always an asset for Alexander's campaigns strategic planning, following his concern for climate, transportation, geography, agriculture and cultural information. "In his short career Alexander completely changed the face of war. More than any of his predecessors he demonstrated the fundamental tactical principles of concentration of force, co-operation between different arms, and a sustained logistics by living off the land" (Hackett, 1989).

The results of the literature review seem to be in agreement with experts' opinion. According to them, Alexander the Great remains until today, the leader who has changed the warfare art significantly. He presented proactive action as also as an innovative, integrated and reasonable approach. His campaigns' assessment according to experts, provide evidence that his success was not a surprising outcome. He managed to embody SC planning into his strategic plans, just as any modern-day military and business leader should incorporate his needs in order to deliver and safeguard the competitive edge. He achieved speed action and managed to deliver more by handling less. He presented flexibility when required and innovative spirit by changing the transportation means or the troops' size and formation. According to experts, he did not follow the "business as usual" spirit not even after the initial success of his campaign. Alexander had always been prepared in detail for the next area to conquer by setting the most capable information network and receiving feedback from his carefully selected subordinates. Information and research were fundamental factors for Alexander's decisions. Finally, experts agree that one of the most significant technique concerning his success is that he established one single point of control, himself, thus integrating SC at the strategic decision level. That was the best way to deliver and maintain competitive advantages in the hostile areas of marching and fighting. Alexander practiced and implemented 2,372 years ago notions that some agencies and companies are struggling to learn and adopt today. Information sharing, monitoring, benchmarking, auditing, training and being proactive provide the competitive edge and deliver satisfactory results. Concluding, experts were asked to identify the key factors that assisted Alexander to succeed in his campaign. The analysis of their answers ends up to the following: Leadership, Integration of SC forecasting and strategic planning, detailed Information sharing network, Command and Control abilities, and Political/Diplomatic skills. Accordingly, they defined the key factors concerning Alexander's SC planning, and the results were: Innovation, time, detailed and properly adjusted Preparation, Knowledge, Flexibility and Host Nation support.

Modern Era Deployment Examples. Based on the results as presented above, certain modern era deployments were reviewed, which present evidence of Alexander's approaches positive effect. In accordance, operational inefficiencies, weaknesses, and gaps could have been avoided and overpassed if Alexander's notions and tactics were incorporated into modern-day leaders' SC planning.

Everyone agrees that even the most excellent strategy is effective only if its execution delivers the desired results. Full of promise plans entirely failed in the battlefield due to limited preparation, wrong decisions or a missing SC link. Deployments to Iraq and Afghanistan uncovered shortcomings in the AFs supply chain planning and provided the right momentum and 
incentives for change. It has taken a long for the modern AFs' leaders to adapt to the characteristics of operating in the Asia region, yet progress has been made over the past years (Wiles \& Chinn, 2010).

An example of successful integration of SC planning - since after inefficiencies were detected - into strategic decision level may be presented from the Persian War or Gulf War I (1990 - 1991). A Joint Allied Force (34 nations led by the U.S.) was fighting against Iraq in response to Iraq's invasion of Kuwait. General Colin Powell, Chairman of the U.S. Joint Chiefs of Staff, served as a liaison between the Army and President George Bush. The implementation of their intention was General Norman Schwarzkopf's battlefield responsibility. The three of them developed the strategic plan which required that the equivalent of Alaska's inhabitants and their personal provisions have to be prepared for deployment and be transported to the Middle East. Lieutenant General Gus Pagonis was the dedicated official to execute the logistical part of the plan (single point of control). Following the success invasion, Powell gave much of the credit to Pagonis. Later, Pagonis described the SC plan he developed for the Gulf War, as based on the approaches of Field Marshal Erwin Rommel and Alexander the Great (Van Mieghem, 1998). The key factor for that successful implementation of his plan was that Pagonis had complete authority for all logistics: land, air, sea, and rail. He was able to direct share crucial information with the Chief of Command and incorporate SC priorities among the final execution plan. Due to that authority, Pagonis was able to successfully control over the SC planning and move the forces and provisions the right time to the right place in the correct order. For the record, land operations lasted just 100 hours (The Directorate of Research, 1995).

At the time of Iraq War or Gulf War II (2003 - 2011), the invasion started with the U.S. joined by the U.K. and other allies. The U.S. General Tommy R. Franks delivered the attack plans for the "Operation Iraqi Freedom", not under conventional notions, but enforcing a rapid and quick responsive force capable of speed attacks. His strategic plan, based on speed more than mass, had profound implications for the SC planning of that operation, like Alexander's technique years ago. Another challenge for the U.S. Armed Forces that time was to achieve the integration of the four operating branches. To confront this problem, General Franks created a single logistics control point to facilitate mutual reliance and communication among the four branches, and all of them used this single network. On the other hand, during that war, U.S. leaders tediously learned a lesson. Before the ground attack, 60 days of supplies were planned to be transferred in the battlefield. In real terms, the capability of sending such amount of supplies was proved, but no one could monitor the containers, thus resulting in missing or broken SC links. Finally, the half of the transported supplies was never used $(40,000$ containers). This example reveals the fact that if inventory is just well-stocked, that does not add value. It has to be feasible to monitor the supply and to transfer it the right time, to the right place, in the correct order. Effective SC should guarantee the knowledge of what and where the AFs have and manage the flow of that, following the battlefield requirements and the strategic planning (Morales \& Geary, 2003).

For the same allied operation, UK AFs faced severe deficiencies during the extremely demanding deployment to Iraq. SC weaknesses and shortcomings became very clear and provided an impetus to make improvements. Based on the British House of Commons Defence Committee's review concerning SC performance, shortfalls occurred, like insufficient and inaccurate SC planning and static and unadaptable demand forecasting. Also, an inadequate deployment infrastructure and deployment's inventory deficiencies were unveiled. Finally, SC proved to be not synchronized with action and performance indicators did not exist (House of Commons Defence Committee, 2004).

According to experts' opinion, that keynote examples of modern era deployments reconfirm that a good SC plan is the basis for success in addition to the fact that Alexander remains the greatest military geniuses of all times. According to them logistics and SC planning are a deterring confrontation but under Alexander's inspirations, it is possible to overcome. Every battlefield area may have some degree of predictability, so the most important thing is to integrate SC with DMP and incorporate predictability, and information to conserve the necessary supplies. Proactive, secure support of host or neighbouring nations will result in establishing a steady flow to force units, thus delivering proper support where and when it is required. Alexander was able to conquer the Persian Empire with an out-numbered army, in an unknown area, against people defending their land. Experts identified the above deployment examples as keynote profoundly under the shadow of Alexander's pioneer tactics.

It is evident that General Franks at the time of Iraq War, preferred speed on mass accordingly to Alexander notion to keep his army on purpose small in number $(<40,000)$, thus maximizing speed and flexibility. Alexander also forced marching to reduce the required amount of supplies and restraint the time needed. Alexander created alliances with regional nations and friendly locals to ensure resupply along campaign's routes. Accordingly, Joint Allied Forces proactively arranged the 
use of territorial nations' transportation air and ground secured routes. Full authority of General Pagonis and the single logistics control point of General Franks reveal an example of successful Alexander's insights' implementation.

Experts state that is the multitasking aspects of Defence sector and special characteristics of military operations result in the urgent need for the SC planning and the decision-related issues to be directed in a holistic and integrated way. National SC systems and independent frameworks cannot support an Allied Joint Force efficiently. Finally, incomplete transparency and partial monitoring of resources, result in additional supplies, while at the same time worldwide, significant equipment, financial inefficiencies and outnumbered military forces are confronted.

\section{Discussion and Proposals}

Studying the literature review and analyzing experts' opinions, it becomes apparent that there are many striking parallels between Alexander's ancient Macedonian army and today's military operations. The rapidly changed global environment demands efficiency at all costs. The rapid shifts in the security sphere do require fast, flexible and sustainable AFs. Rising costs due to technology advances under budgets cutbacks, state that no Nation can overpass critical decisions and choices. Future deployments seem to require smaller AFs but with the same capability while corresponding reductions in the Defence sector are unavoidable. Integration, collaboration, sharing and effectiveness are more than needed. Thus, a constant, integrated DMP framework concerning the SC forecasting and planning has to be designed and regularly implemented during the whole spectrum of military procedures and activities.

The basic principles and the key factors that influenced Alexander concerning planning and led to his legendary campaign may still provide a tremendous impetus for the modern era defence sector. It seems that recent reformation efforts have been the lessons' learned positive outcome. Both the U.S. and U.K. DoD have decided to identify precisely the weaknesses and redesign and integrate SC planning into DMP, thus improving effectiveness, enhancing flexibility, achieving savings and adding value. In this context, an integrated SC forecasting and planning capability has to be set to support the DMP holistically, optimize the operational planning, safeguard information sharing and deliver transparency and monitoring of the supplies and services flow.

The results of this study reveal the urgent need for increasing the effectiveness of logistics support and SC performance. SC planning, performance management, and supply processes are identified as weak areas by both defence and business experts. Though, it is apparent that progress has been achieved the recent years. All Alexander's techniques may not be enforced, but most of Alliance's armies may now anticipate SC delays, follow alternative routes and mitigate even partially inefficiencies impact through relative SC planning and DMP models. Most experts agree that transparency, certainty, flexibility and authority should be the principles of an active SC planning. These principles will lead to the achievement of goals like constant and sustainable battlefield support, agency integration and performance benchmarking.

Defence sector has to start by planning as quantified as possible even though all data may not be available. Quantification will assist cost reductions, will reduce system failures and shortfalls, will enforce performance benchmarking, will upgrade transparency and will make feasible the setting of viable objectives. Another one important factor is also to get leadership consensus and commitment. Cross-functional teams have to be set in order to overcome conventional mindset, emotionally driven behaviours and internal interests. "Out of the box" approaches and innovation have to be encouraged. Performance management, IT systems and mindset and cultural change have to be parallel developed. IT systems should provide monitoring and will then assist in building up one joint inventory and SC management system for all the army branches. Providing supplies for modern military operations demand high budgets, so benchmarking performance is essential.

Through studying the example of Alexander the Great and the lessons learned concerning the way he integrated SC planning into strategic decision level, Defence sector nowadays may find the appropriate instruments to rebirth the SC planning and efficiently combine the IT systems and technological advantages. Integration and optimization of SC will provide military leaders with more efficient logistics support to operations, will maximize efficiency, will define the optimal number in supplies to ensure operational capabilities, will provide transparency and even more will encourage collaboration among allied forces (NATO, 2012).

\section{References}

[1] Andrejevas, K., (2010), Operational Art and Lithuanian Armed Forces in next 10 Years Logistical achievements of Alexander the Great and Lithuanian Armed Forces Logistics, The Bugle, 8-11 
[2] Bryant, A., (2002), Re-grounding grounded theory, JITTA: Journal of Information Technology Theory and Application, $4(1), 25$

[3] Cantrell, R., (2003), Understanding Sun Tzu on the Art of War, Arlington, VA, USA: Center For Advantage

[4] Charmaz, K., (1983), The grounded theory method: An explication and interpretation. In R. Emerson (Ed.), Contemporary field research: A collection of readings (pp. 109-126), Boston, MA: Little Brown Company

[5] Engels, D. W., (1980), Alexander the Great and the Logistics of the Macedonian Army, Berkeley, CA, US: University of California Press

[6] Fuller, J., (2004), The Generalship of Alexander the Great (5th ed), Cambridge, MA: Da Capo Press

[7] Hackett, G. S., (1989), Warfare in the Ancient World, New York, New York: Facts on File Inc

[8] House of Commons Defence Committee, (2004), Lessons of Iraq, London: The Stationery Office by Order of the House

[9] Keegan, J., (1988), The Mask of Command. Harrisonburg, VA: Penguin Books

[10] Morales, D. \& Geary, S., (2003), Speed Kills: Supply Chain Lessons from the war in Iraq, Harvard Business Review, 81 (11), 16-17

[11] NATO, (2012), NATO Logistics Handbook, Brussels, Belgium: NATO HQ, Defence Policy and Planning Division

[12] Pagonis, W. G. \& Cruikshank, J. L., (1992), Moving Mountains: Lessons in Leadership and Logistics from the Gulf War, Boston: Harvard Business School Press

[13] Pederson, R. B., (1998), A Study of Combined Arms Warfare by Alexander the Great, (retrieved August 12 $2^{\text {th }}, 2016$, from Defense Technical Information Center (DTIC®): http://www.dtic.mil/dtic/tr/fulltext/u2/a350056.pdf)

[14] Sticz, L., (2008), Logistic Planning and the Operations Logistic Chain Management, AARMS , 7, 485-504

[15] The Directorate of Research, (1995), Gulf War Logitics: Theory into Practice, Maxwell AFB, AL, U.S.A.: U.S. Air command and staff College

[16] UK Ministry of Defence, (2003), Joint Warfare Publication 4-00 (JWP 4-00): Logistics for Joint Operations, The Joint Doctrine \& Concepts Centre

[17] Van Mieghem, T., (1998), Lessons Learned from Alexander the Great. Quality Progress Monthly, 31 (1), 41-46

[18] Wiles, M. \& Chinn, D., (2010), Supply chain transformation under fire, London: McKinsey \& Company 